Divers@ Revista Eletrônica Interdisciplinar,

Matinhos, v. 14, n. 2, p. 148-165, jul./dez. 2021

ISSN 1983-8921

doi: http://dx.doi.org/10.5380/diver.v14i2.82115

\title{
Y-CIDAD DE LA EDUCACIÓN INCLUSIVA
}

\author{
Y-CIDAD OF INCLUSIVE EDUCATION \\ Y-CIDAD DE EDUCAÇÃO INCLUSIVA
}

Aldo Ocampo González ${ }^{1}$,

\begin{abstract}
Resumen
Este trabajo explora aquello que habita entre los dos términos de constitución del sintagma 'educación inclusiva'. Esta preocupación inaugura una singular cópula heurística, una entridad y un punto de conexión/ mutación de muchas cosas que viajan y se movilizan en diversas direcciones. La educación inclusiva inaugura un movimiento continuo hacia lo otro, configurando un espacio indeterminado de producción, distanciándose del pensamiento arborescente o normativo rector en la comprensión de variados marcos epistemológicos. Es un saber que se construye en lo no-visto, en aquello que habita más allá de lo instituido. El pensamiento de la educación inclusiva a diferencia del proporcionado por la educación especial devela un marcado carácter relacional, no es esencialista, es posicional, heterogéneo, contingente y contradictorio. Cada una de estas características informa que la naturaleza de su pensamiento se define por momentos de singulares disputas que saltan y se movilizan hacia rumbos desconocidos, denotando una posición móvil e itinerante de frontería. El trabajo concluye observando que, la inclusión debe avanzar hacia la elaboración de una estrategia que nos permita articular una comprensión global de sus modos de producción de la subjetividad, en otras palabras, profundizar en las dinámicas de configuración y procesos de singularización del ser, siendo justamente esto último, lo que la educación inclusiva es incapaz de comprender a través de sus modos e itinerarios de definición del ser regulado por un sistema de equivalencias categoriales.
\end{abstract}

Palabras clave: conjunciones analítico-metodológicas; epistemología; objeto teórico; razón teórica.

\begin{abstract}
This work explores what lives between the two terms of constitution of the phrase 'inclusive education'. This concern inaugurates a singular heuristic copula, an entrity and a point of connection / mutation of many things that travel and move in different directions. Inclusive education inaugurates a continuous movement towards the other, configuring an indeterminate space of production, distancing itself from the arborescent or normative thinking that governs the understanding and treatment of various epistemological frameworks. It is a knowledge that is built on the unseen, on that which lives beyond the instituted. The thought of inclusive education, unlike that provided by special education, reveals a marked relational character, it is not essentialist, it is positional, heterogeneous, contingent and contradictory.
\end{abstract}

\footnotetext{
* Artigo Original: Recebido em 26/07/2021 - Aprovado em 02/12/2021.

${ }^{1}$ Centro de Estudios Latinoamericanos de Educación Inclusiva CELEI), Santiago, Chile. e-mail: aldo.ocampo@celei.cl ORCID: https://orcid.org/0000-0002-6654-8269 (autor correspondiente)
}

* Apoio financeiro: Este trabajo contó con el apoyo financiero del Programa Investigadores en Residencia (PIR) del Centro de Estudios Latinoamericanos de Educación Inclusiva (CELEI), Santiago, Chile. 
Each of these characteristics informs that the nature of their thinking is defined by moments of singular disputes that jump and move towards unknown directions, denoting a mobile and itinerant frontier position. The work concludes by observing that inclusion must advance towards the elaboration of a strategy that allows us to articulate a global understanding of its modes of production of subjectivity, in other words, to delve into the dynamics of configuration and processes of singularization of being, being precisely the latter, what inclusive education is unable to understand through its modes and itineraries of definition of being regulated by a system of categorical equivalences.

Keywords: analytical-methodological conjunctions; epistemology; theoretical object; theoretical reason.

\section{Resumo}

Este trabalho explora o que existe entre os dois termos de constituição da frase 'educação inclusiva'. Essa preocupação inaugura uma cópula heurística singular, uma entrada e um ponto de conexão / mutação de muitas coisas que viajam e se movem em diferentes direções. A educação inclusiva inaugura um movimento contínuo em direção ao outro, configurando um espaço indeterminado de produção, distanciando-se do pensamento arborescente ou normativo que rege a compreensão dos diversos quadros epistemológicos. É um conhecimento que se constrói no invisível, naquilo que vive além do instituído. O pensamento da educação inclusiva, ao contrário do que é proporcionado pela educação especial, revela um caráter relacional marcado, não é essencialista, é posicional, heterogêneo, contingente e contraditório. Cada uma dessas características informa que a natureza de seu pensamento é definida por momentos de disputas singulares que saltam e se movem em direções desconhecidas, denotando uma posição de fronteira móvel e itinerante. $\mathrm{O}$ trabalho conclui observando que a inclusão deve avançar no sentido da elaboração de uma estratégia que nos permita articular uma compreensão global dos seus modos de produção da subjetividade, ou seja, mergulhar nas dinâmicas de configuração e nos processos de singularização do ser, ser. precisamente o último, o que a educação inclusiva não é capaz de compreender por meio de seus modos e itinerários de definição de ser regulada por um sistema de equivalências categóricas.

Palavras-chave: conjunções analítico-metodológicas; epistemologia; objeto teórico; razão teórica.

\section{Introducción: Y-cidad de la educación inclusiva}

¿Qué es lo que habita entre los dos términos de constitución del sintagma 'educación inclusiva'? Hace un par de años me surgió esta pregunta que considero relevante para poder develar los mecanismos de interactividad que entran en contacto al momento de conformar el esquema heurístico de lo inclusivo. Este complejo ejercicio analítico será informado a través de la contribución de Felman (1978), Rajchman (2004), Mengue (2008) y Bal (2018). La pregunta por aquello que habita entre ambos términos del sintagma configura una singular cópula heurística, una entridad y un punto de conexión/mutación de muchas cosas que viajan y se movilizan en diversas direcciones.
Y-cidad es una noción que tomo prestada de la brillante obra de Mieke Bal, para explicar los múltiples usos de ' $y$ ' en la configuración heurística del sintagma. Esto nos permite reflexionar sobre sus dos secciones: lo educativo y lo inclusivo; articulando un efecto alter-epistémico que se interroga acerca de qué es lo que ambos términos aprenden mutuamente, o bien, que aprende la sección 'educación' de lo 'inclusivo' y viceversa. Por tanto, refiero a la conjunción de múltiples elementos que participan de sus contornos definitorios y que permiten ofrecer una respuesta contingente a la interrogante: ¿cómo se relacionan educación e inclusión?, la que no es el resultado de un conjunto de elementos aglutinados, sino rearticulados, en relación a, traducidos $\mathrm{y}$ ensamblados para dar paso a algo completamente nuevo. Y-cidad es sinónimo de una operatoria 
constructiva de múltiples relaciones, nunca de una acumulación paratáctica de elementos, desplaza la fuerza de la aplicación por la potencia analítica de la implicación, lo que a juicio de Bal (2018), sugiere "un impacto mutuo que no es jerárquico; un pliegue del uno sobre el otro, una interioridad mutua. Tengamos presente ese repliegue entendido como implicación mutua" (p.189). Sin embargo, es difícil saber lo que es exactamente la educación inclusiva, acto que es necesario interrogar desde diversas perspectivas para intencionar un sistema de remoción y dislocación de sus unidades de ensamblaje conocidas y conducentes a un sistema de falsificación persistente.

La lógica de funcionamiento que sigue la y-cidad es algo que se construye y constituye bajo la forma de la multiplicidad, inaugura una espacialidad heterológica y heterogenésica, como sostiene Mengue (2008), un sistema heterogéneo de lo heterogéneo. La primera operación heurística que designa la y-cidad de la educación inclusiva es el estudio de las conexiones e interacciones entre ambas secciones del concepto, es decir, "de lo abierto, esto es, de la conectividad, de aquello que sólo se cierra para abrir" (MENGUE, 2008, p.12). ¿Cómo son implicados cada uno de los elementos que entran en contacto? Una respuestade-lo-posible reside en el argumento que señala que, "sin duda, no contra la posibilidad de cualquier determinación y tampoco contra la existencia de un algo determinado" (MENGUE, 2008, p.13). Es una operación que acontece en lo indeterminado, aquello que "no es lo contrario de lo determinado sino su condición, aquel ámbito lógico u ontológico que hace posible cualquier determinación y que permite a los determinados existir unos junto a otros aun cuando resulten incapaces de componerse" (MENGUE, 2008, p.13). La educación inclusiva es un territorio en el que se entrelazan y unen múltiples recursos formando un campo de pluralización conceptual. La pregunta por las modalidades de interacción y comunicación entre ambos términos debe reinventarse, especialmente, a la luz de un diálogo experimental a partir de cuerpos de conocimientos y lenguajes completamente diferentes.

La pregunta por la y-cidad nos conduce a una reflexión acerca de cómo los términos 'educación' e ‘inclusión' se comunican, interactúan e informan mutuamente, a partir de las preocupaciones más íntimas de este campo de investigación crítica. La pregunta por aquello que habita entre ambos términos del sintagma puede aclararnos acerca de aquellas cosas que entran en contacto inaugurando modos de conocimientos diferentes. Para William (2017), esta relación documenta "una preocupación principal por lo que uno nunca puede dominar o superar". Lo cierto es que ambos términos se comunican a través de un corpus heterogenésico de temas comunes a cada uno de ellos, explicando que tal interacción no puede ofrecerse desde marcos intelectuales convencionales. Las personas que nos dedicamos al género heurístico llamado 'educación', 'ciencias de la educación' o 'pedagogía' disfrutamos de una gran herencia de pensamiento que es legible en todo el globo, el problema aparece cuando nos preguntamos por la fuerza teórica, metodológica, política y ética que reside en lo más profundo del calificativo 'inclusiva' o del sintagma 'educación inclusiva', un espacio desconocido, construido y justificado erróneamente sobre un conjunto de presupuestos que omiten y marginan la emergencia de su verdadero índice de singularidad. Este hecho documenta qué disponemos de muy poco conocimiento sobre el verdadero alcance, sentido y función de lo inclusivo en el mundo actual y más allá del fallo heurístico que contribuye a justificar su punto de emergencia en tanto sistema de continuidad de lo especial imposición del modelo epistémico y didáctico de educación especial-. La y-cidad como herramienta heurística entraña otra pregunta: ¿qué nuevos puntos de apertura, imaginación y agitación del pensamiento educativo pueden arrojar nuevas luces a partir de la presencia del calificativo inclusiva?, ¿qué innovaciones epistémico-conceptuales ofrece el calificativo para pensar un amplio abanico de problemáticas propias del mundo actual. Es necesario encontrar la especificidad del término y del sintagma. No porque abunden altos índices bibliométricos quiere decir que estemos hablando desde la autenticidad del fenómeno.

Las premisas documentadas anteriormente dan cuenta de un singular relacionamiento por desnivel, aunque el calificativo y el sintagma son tan conocidos y empleados por la comunidad de práctica, no sabemos mucho acerca de su constitución y morfología heurística. Nos encontramos en presencia de un concepto ampliamente difundido, vago, impreciso y atravesado por un exceso de significado que explicita su punto de debilidad en torno a la ausencia de bloques de reflexividad que permitan recuperar su índice de singularidad. Esto demuestra que no sabemos qué es la educación inclusiva en su especificidad, en tanto campo de 
investigación y ámbito de formación emerge a través de diversos tópicos constructivos, los que no siempre logran recuperar la interrogante acerca de su naturaleza epistemológica. La relación entre ‘educación' e 'inclusión' nunca ha sido igual a igual, tampoco pueden ser comprendidas como un simple mecanismo de contraste, sino que debe trabajar para redescubrir un signo complejo, desconocido y en mutación permanente. La analítica por la y-cidad de la educación inclusiva es una operación clave en la creación de una nueva sensibilidad investigativa crítica que nos invita a entender-de-otro-modo su campo de problemas y ensamblajes. Inaugura así, un nuevo contextualismo epistémico y un campo de meta-receptividad constructiva.

En lo que sigue focalizaré el análisis en torno a las conjunciones que acontecen en la intimidad del espacio que habita que entre las dos secciones del sintagma 'educación inclusiva'. Esta operación escapa a los confines de las categorías conocidas. Ambas secciones son informadas por diversos proyectos de conocimientos, compromisos éticos, programas políticos, conceptos, territorios, sujetos, métodos, metodologías, etc. Esto demuestra, en parte, que el calificativo 'inclusiva' documenta una larga data en diversos campos de investigación y prácticas críticas desplegadas por innumerables movimientos sociales contemporáneos, sin denominarse de esta forma, los que reafirman un punto de aleación con la estructura profunda del conocimiento de la educación inclusiva, demostrando una relación paradojal y excéntrica. $\mathrm{Si}$ bien, numerosos campos pueden referirse al fenómeno, ninguna de estas puede explicar el fenómeno o simplemente contenerlo. Este hecho heurístico es crucial en la caracterización de su objeto. Este punto será retomado en apartados posteriores. La y-cidad se convierte en un vector de alteración acerca de las formas en que pensamos la formación del campo denominado educación inclusiva, abre nuevas posibilidades para la experiencia y nuevos modos de comprensión que da cuenta de nuevas formas de contacto y de relacionarse; documenta "una serie de compromisos y de deudas que no cesan de serle atribuidos aun cuando no sean los suyos" (MENGUE, 2008, p.10). La y-cidad se convierte en un espacio de movilización del pensamiento, un conjunto de problemas y de elaboraciones conceptuales y metodológicamente desconocidos.

La y-cidad es propio de los sistemas epistemológicos abiertos, diaspóricos y nomadistas, lo abierto en tanto modalidad constructiva favorece las conexiones, la acción copulativa y la lógica de los múltiples entres, inaugurando un nuevo espacio heurístico que desdibuja los modos de producción hegemónicos del conocimiento. La educación inclusiva como estrategia analítica no habita un espacio armónico, ni tranquilo ni mucho menos claramente definido. Es un lugar de múltiples disensos que develan una "conciencia tan compleja e íntima de sensibilidad a las complejidades de sus problemáticas" (BOWMAN, 2010, p.231) y apremiantes del mundo actual. La y-cidad se abre a la conciencia de las genealogías imbricadas y líneas de fuerza que han constituido y estructurado los desarrollos heurísticos del territorio. Observa demás, cómo son desplazados un conjunto de "movimientos que condicionan y sobredeterminan tales campos académicos y otras distancias, relaciones, encuentros, hibridaciones, rupturas de los discursos culturales y consolidaciones" (BOWMAN, 2010, p.231).

¿Cuál es el otro del objeto teórico, empírico y analítico de la educación inclusiva? Este campo de investigación cubre una multiplicidad de posibilidades, a pesar que superficialmente cada una de sus temáticas se encuentra coordinado o entrelazado, en la profundidad del mismo no operan así. La educación inclusiva no designa fácilmente un campo especificable, a pesar que muchos de sus tópicos de análisis se encuentran inter-implicados. Los efectos de la y-cidad pueden ser leídos en términos de

[...] diagrama se concibe como una máquina autopoiética que no solo le otorga una consistencia funcional y material, sino que le exige desplegar sus diversos registros de alteridad, liberándolo de una identidad encerrada en simples relaciones estructurales" (Guattari, 1995a, pág.44). "Liberar" aquí se aplica a escapar de un "orden esquemático" predeterminado impuesto a la máquina, que funciona en el horizonte de la muerte y la destructibilidad. El uso que hace Guattari de Diagrama se opone a la idea de la reproducibilidad misma de una máquina técnica (como en la computadora y sus partes) (PANAYOTOV, 2016, p.s/r.). 
Si el terreno epistemológico de la educación inclusiva se construye a partir de múltiples convergencias heurísticas, entonces, sus mecanismos de constitución acontecen en el movimiento y en el entremedio de muchas cosas, las que son rearticuladas y traducidas. Entiendo el lugar de la falta y la incompletud como el lugar de lo posible y de acontecimiento de lo nuevo. Gracias a la apertura del campo es posible "la determinación, la institucionalización, la estabilización y la cristalización” (ORLANDI, 2012, p.59).

\section{Educación inclusiva: Un concepto amplio y no-fijo para leer diversas categorías teóricas, se convierte en una forma de pensamiento móvil}

Tal como he sostenido en trabajos anteriores, el conocimiento de la educación inclusiva se construye en el movimiento, en el pensamiento de la relación, en el encuentro y en la constelación de múltiples recursos constructivos completamente diferentes uno de otro, los que, al encontrarse, dialogar, interactuar, etc., producen destellos imaginativos, dando paso a sistemas intelectuales, categoriales y metodológicos desconocidos. Epistemológicamente, la educación inclusiva entre sus propósitos heurísticos contempla la movilización de la frontera del conocimiento -produce umbrales y prácticas de investigación emergentes- creando un nuevo campo y objeto atravesado por diversos enredos genealógicos y trayectorias rizomáticas, pero, que no le pertenece a ninguno de ellos, con exclusividad, solo participan de su ensamblaje. Por supuesto que, la exterioridad heurística que configura su campo de producción no es ajena a diversas clases de contaminaciones, mediaciones, traducciones, rearticulaciones y depuraciones de diverso tipo. Ningún recurso confluyente posee la capacidad de mantenerse intacto, todos, a su forma, mutan, se alteran, se transforman; inaugurando nuevos objetos de trabajo cruciales en el devenir de la ciencia educativa y de muchos otros campos de indagación contemporáneos vinculados directa o indirectamente a ella. Disfruto entendiendo la educación inclusiva como una construcción-de-loposible.

Cabe recordar que, la inclusión como fenómeno heurístico y político afecta y cruza a un repertorio significativo de geografías intelectuales dispersas; interrogando y trasgrediendo aquello que habita en los límites de diversos proyectos disciplinarios, inter- y trans-disciplinarios, posicionando la mirada en aquello que puede ser visto, escuchado y enunciado en un complejo y desconocido 'más allá. Es en esta espacialidad que lo inclusivo despliega su fuerza y capacidad teórico-metodológica y político-ética. De ahí, su naturaleza post-disciplinar - un espacio de encuentro de problemas, conceptos, sujetos, territorios, proyectos políticos, teorías, compromisos éticos y métodos de trabajo que históricamente no han sido bien recibidos en la intimidad de lo educativo tanto desde un punto de vista teórico como institucional-. Nos enfrentamos a un objeto que tiene por misión producir complejos efectos en el presente, no solo porque desestabiliza el logos, sino que, especialmente, por interrumpir en las lógicas de producción del conocimiento de diversos proyectos académicos significados bajo el argumento y legado de lo crítico. La educación inclusiva es un campo de múltiples agenciamientos heurísticos, "una constelación de ideas, preocupaciones, posicionamientos, intervenciones y teorías que conforman un pensamiento" (HERNÁNDEZ, 2016 , p.7) cuya principal característica es que es modulado a través de giros y rearticulaciones inesperadas y desafiantes. Nos enfrentamos así, a una lectura discontinua de sus múltiples herencias y recursos heurísticos-metodológicos. Todo ello, denota un esquema analítico móvil que acontece en el pensamiento del encuentro, de la relación, de la constelación, algo dado-dándose-por-dar.

Epistemológicamente, la educación inclusiva puede ser explicada de mejor manera a través de la metáfora del viaje entre una extensa multiplicidad de objetos, teorías, compromisos éticos, proyectos políticos, conceptos, sujetos, territorios, métodos, etc., un territorio aléctico y heterogenésico caracterizado por desplegar una acción heurística de carácter 'in-’ y 'post-'disciplinar, construye una frontería epistémica, un espacio de indeterminación generativa en la producción de un saber que disloca los modos de ordenamiento que erigen las tareas de los diversos sistemas-mundo. Todo ello, permite sostener que, su objeto no puede ser definido fácilmente en los paradigmas de ninguna disciplina actual, producto que su campo de fenómenos y red objetual desborda el purismo normativo proporcionado por las epistemologías tradicionales y diversos proyectos de conocimiento que hasta ahora han participado como informantes clave en el desarrollo de su teoría. $\mathrm{Su}$ heurística impone un acto de leer de nuevo evitando dar por sentado cada uno de sus fenómenos. La 
educación inclusiva desafía y revoluciona la teoría educativa contemporánea desde las afueras de su quehacer científico. La producción de futuros

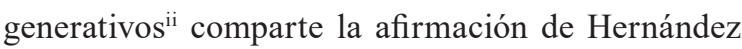
(2016), acerca del presente como "el momento de la lectura y el lugar de producción de sentido" (p.9) al interactuar con una amplia variedad de fenómenos.

Tanto el movimiento y el desplazamiento como condición clave en la producción del conocimiento de la educación inclusiva puede encontrar parte de su fundamento en la crisis de los límites de las disciplinas tal como las hemos conocido. Tal ruptura es clave para entender que el verdadero argumento de lo inclusivo se inscribe mucho más allá de las clásicas normatividades que lo definen esencialmente a partir de lo 'especial' o como disfruto significando: régimen especial-céntrico. En efecto, añade Hernández (2016), la "crisis de la frontera moviliza los significados y los modos de leer e interpretar que se habían repetido e instaurado en las disciplinas" (p.9). Examinemos a continuación, parte de la contribución de Zemelman (1992), en torno al movimiento como condición de producción del conocimiento. Posteriormente, referiré al papel de las transposiciones como arma crucial para entender las nuevas configuraciones del conocimiento de lo inclusivo. Nos enfrentamos a un pensamiento móvil, es algo que

[...] deja estelas, que cambia las cosas, que introduce lo nuevo en el espacio de lo viejo, que conecta lugares, que lleva y trae ideas, interpretaciones, afectos... y, al mismo tiempo, un pensamiento limítrofe, que diluye y tambalea las fronteras, que las rompe, que las moviliza y las disuelve. Sin embargo, esta movilidad continua adquiere su sentido último en el instante en que el desplazamiento se detiene y produce pequeños intentos de encuentro en los que los tiempos, los sujetos, las teorías, las disciplinas, los métodos, los afectos, se entrelazan, confluyen, conversan, colisionan y tienen contacto. (HERNÁNDEZ, 2016, p.10).

La educación inclusiva inaugura un movimiento continuo hacia lo otro, configurando un espacio indeterminado de producción, distanciándose del pensamiento arborescente o normativo rector en la comprensión de variados marcos epistemológicos. Es un saber que se construye en lo no-visto, en aquello que habita más allá de lo instituido. Desafía los medios de producción y los circuitos de legitimidad del círculo de reproducción sancionado por tales marcos heurísticos. Una de las principales manifestaciones del campo de fenómenos de lo inclusivo queda atravesado por el movimiento, documentando cómo estos sistemáticamente cambian de posición y multiplican las perspectivas, igual que cambian los matices interpretativos de su red objetual. Es esto lo que permite definir al sintagma como un concepto amplio y no-fijo que interactúa con diversas clases de categorías y prácticas teóricas, sociales y políticas, ofrece un nuevo marco interpretativo acerca de su campo de fenómenos que trabaja en contra de cualquier forma de pureza epistémica, atendiendo a las fluctuaciones del tiempo presente.

Tal operación sugiere recomponer el diálogo acerca de la multiplicidad de objetos de análisis que cuentan como parte de la educación inclusiva informando cómo este funciona $\mathrm{y}$, con ello, propiciando nuevos encuentros a través de múltiples y estratificadas convergencias heurísticas. Sus demandas teóricas exigen disponer de una ética de la inconmensurabilidad para atender a la multiplicidad de problemáticas que conforman su centro de análisis, convirtiéndose en un dispositivo crítico de vigilancia para la emergencia de un espacio-lugar atravesado por coordenadas de dicha naturaleza. Se convierte en un mecanismo clave para desbloquear los aspectos confusos de la educación y su vinculación con diversos proyectos de justicia, sacando de la invisibilidad las estructuras del colonialismo educativo, reconoce que, habrán "partes del proyecto de descolonización que no son fácilmente absorbidas por enfoques de equidad educativa basados en los derechos humanos o los derechos civiles" (TUCK; YANG, 2012, p.4). Esta ética es lo que permite conocer lo que es distinto, lo que habita en el centro crítico de la multiplicidad, aquello que estructura el principio de relaciones exteriores y de heterogénesis; dos axiomas claves en la construcción epistemológica de lo inclusivo que informan cómo múltiples elementos en su naturaleza colaboran en el ensamblaje del campo cuyo hábitat es la traducción. 


\section{La pregunta por el objeto}

La pregunta por el objeto de la educación inclusiva constituye un punto espinoso, no es algo sencillo de definir. Para Bal (2003), la pregunta por el objeto es lo primero junto al método, ambos dan como resultado la proliferación del campo. La pregunta por el objeto nos conduce a la exploración de la base epistemológica y del estatus de esta. Si bien, para ambas dimensiones ya he ofrecido algunas respuestas, retomaré en esta sección tales contribuciones para organizar un análisis mucho más complejo. La pregunta por el objeto exige cartografiar el estatus epistemológico del territorio. Para develar el objeto de la educación inclusiva es preciso ahondar en la naturaleza de su base epistemológica que en este caso se encuentra definida por parámetros de carácter post-disciplinar, esta no puede ser delimitada en términos de disciplina ya que su red objetual se compone de elementos de diversa naturaleza los que difícilmente pueden ser consensuados y categorizados en torno a hipótesis y objetivos definidos. Incluso sus límites regionales son difíciles de determinar producto de la amplia multiplicidad de elementos que en ella confluyen.

El dominio del objeto de la educación inclusiva es algo que debe ser creado/producido a partir de las operaciones de traducción y rearticulación de cada uno de sus recursos constructivos. Una advertencia antes de avanzar en la argumentación: la educación inclusiva no es el otro ascendiente directo de la educación especial. Este argumento nos conduce a dos preguntas: ¿cuál es el objeto de la teoría de la educación inclusiva? y, si sostenemos que, la educación especial es una forma de inclusión, mientras que, la inclusión no es una forma de lo especial, entonces, ¿cuál es el otro de la teoría de la educación inclusiva auténtica? Esta interrogante opera en varias direcciones. Por un lado, explora las fuerzas definitorias del sujeto de lo inclusivo y, por otro, indaga en un efecto alter-epistémico que aborda el campo comprendiendo de otra forma los engranajes de sus territorios heurísticos.

La creación del objeto de la educación inclusiva entraña la complejidad de producir un nuevo objeto y saber que, si bien, resulta de múltiples enredos genealógicos, es algo que no le pertenece a nadie. Esta es una de las mayores complejidades en la construcción de su objeto, saber y campo. En efecto, Bal (2003), advierte que, "el simple hecho de enumerar las disciplinas que participan en el estudio de este objeto no es suficiente, incluso cuando en sus listas figuren otras (inter)disciplinas contemporáneas. Esto viene siendo la práctica común en recientes publicaciones" (p.3). Para hacer educación inclusiva no basta con elegir un campo o una perspectiva particular académica, construir un método y elaborar un determinado objeto, ya que el trabajo post-disciplinar demanda otras operaciones de funcionamiento, documentando que la constelación de problemas de este territorio no puede ser fácilmente cartografiados. La educación inclusiva no puede ser delimitada siguiendo las clásicas designaciones epistemológicas: elección de un objeto bien delimitable y de un campo fácilmente comprensible. El mismo problema enfrentan los métodos, no basta con la aplicación de uno exclusivamente, o bien, un corpus selecto de estos. La pregunta por el objeto y el método es clave, ambos ensamblan un nuevo campo de investigación. En la intimidad heurística de la educación inclusiva confluye una multiplicidad de objetos los que experimentan complejas transformaciones a través de cada una de sus cadenas y convergencias heurísticas al ensamblar la rostricidad auténtica de la educación inclusiva.

La construcción del objeto de la educación inclusiva se construye de forma diferente a los presupuestos analíticos empleados por los marcos epistemológicos normativos; especialmente, si este objeto al conformarse a través de diversas clases de interacciones y viajes, se construye en la mutación permanente. Los viajes son claves en objetos y problemas que no son fácilmente ubicables en ninguna de las disciplinas actuales o bien, cruzan límites de las clásicas disciplinas creando nuevos ensamblajes heurísticos que resultan relevantes en la emergencia de otras formas de construcción del conocimiento. ¿Qué consecuencias tiene desafiar los límites disciplinarios? Para responder a esta interrogante, haré uso de la brillante contribución de la teórica cultural, Mieke Bal. La educación inclusiva presta atención a un objeto diferente al legado por la empresa dedicada la falsificación de su trama heurística -lamentablemente lo que más conocemos-, reconociendo que, esta legitima la creación de un "nuevo campo contrario a los enfoques tradicionales no ha tenido éxito (lo suficiente) en el desarrollo de una metodología para contrarrestar la exclusión de métodos de las distintas disciplinas. La mayoría de las veces, los métodos no han cambiado" (BAL, 2009, p.9). Es muy frecuente que los objetos 
se transformen, no así los métodos. La educación inclusiva posee un problema de práctica y contenido.

La cuestión principal que expongo en esta sección es la del objeto. Si bien, la educación inclusiva no tiene claro su objeto o la colección de fenómenos o cosas conocidas que cuentan como parte de esta. En diversos trabajos he sostenido enfáticamente la necesidad que la circunscripción intelectual designada como 'educación inclusiva' encuentre su objeto, creo que la complejidad de definición del mismo, exige considerar la construcción de su red objetual sin recurrir a su propiedad real o simbólica. Con ello, no estoy negando el objeto, solo hago parte de la complicidad que impone su complejidad. Es necesario aprender a descifrar e interactuar con los posibles candidatos que se cuelan en su configuración. Los objetos son eventos heurísticos de diversa naturaleza.

¿Cómo ver las mutaciones del objeto de la educación inclusiva a través de sus múltiples enredos genealógicos y campos de información de este? La educación inclusiva se convierte en un espacio de agitación del pensamiento que disloca las formas de visualidad legitimadas por sus técnicas de visualización impulsadas por la modernidad. Las prácticas de visualización en términos heurísticos contribuyen a diagramar, organizar y mostrar determinados fenómenos, los que en el mainstream discursivo de lo inclusivo afianzan la alianza de carácter biopolítica y del humanismo clásico. Por tanto, aquí, nos enfrentamos a un sistema de obstrucción de las prácticas de visualidad del territorio denominado 'educación inclusiva'. ¿Es posible pensar este campo en términos de imagen de pensamiento? Lo visual es algo que se inscribe y opera de forma múltiple en la intimidad del campo, retorna aquí, la pregunta por lo legible y lo visible. La visualidad siempre está atravesada de impureza y sinestesia, sostendrá Bal (2021).

La visualidad de la educación inclusiva se construye, inscribe y desarrolla de múltiples maneras, es decir, se desenvuelve en varias direcciones y sentidos, desafía el estatus ontosemiológico legitimado por el régimen normocéntrico y especial-céntrico, alternando sus implicancias éticas y políticas y sus formas de ver. Lo cierto es que, de cualquier manera, el mainstream discursivo legitimado en las estructuras académicas e investigativas, así como, en diversos programas sociales y políticos a nivel mundial informan que la extensión e imposición de la rostricidad de lo especial en lo inclusivo -convirtiendo a esta última en una extensión o mutación más avanzada del calificativodevela que su ingreso en el campo académico de lo educativo es producido en torno a una imagen desajustada. Las prácticas de visualidad -lo que vemos, lo que nos mira y sus efectos metafóricos-de lo inclusivo deben ir acompañadas de sus dispositivos de visibilidad -espacio de conocibilidad-, ambos denotan una operación analítica de inter-implicación, lo que sugiere que hacerse visible en palabras de Chow (2010),

[...] simplemente una cuestión de volverse visible en el sentido visual (como una imagen u objeto). Más bien, además de las imágenes y los objetos visibles, también hay un sentido en el que la visibilidad debería remitirnos a "la condición de posibilidad de lo que se hace visible". Porque, cualesquiera objetos e imágenes que sean visibles, y la forma en que son visibles, depende de lo que ella llama "este otro sentido epistémico de visibilidad'. La visibilidad y el hacer visible, entonces, es una problemática más compleja de lo que una simple orientación empírica podría comprender (o incluso 'ver'). Las cuestiones políticas de visibilidad implican mucho más que cuestiones empíricas que hacer con la selección y composición de quién o qué está representado dónde y cuándo $\mathrm{y}$ cómo. Es más bien "una cuestión de participar en una política discursiva de (re) configurar la relación entre el centro y los márgenes. (p.243).

Las prácticas de visualidad y visibilidad se convierten en dos recursos claves para examinar la multiplicidad de elementos constructivos del campo, especialmente, brindan la posibilidad de explorar significados compartidos entre cada uno de sus enredos genealógicos. Concebida a así, el beneficio heurístico de la visibilidad se convierte en una práctica de inteligibilidad y de estabilización de sus significantes auténticos. La visualidad se convierte a efectos de este trabajo en un dispositivo epistemológico específico que documenta formas 
específicas acerca del aparato analítico-metodológico de lo inclusivo. Aquí, nos enfrentamos a otro punto caliente: la extraña relación establecida en las formas adjetivales de lo especial y lo inclusivo devela una obstrucción en sus prácticas de visualidad. La epistemología de la educación inclusiva es un dispositivo heurístico que cambia el orden de funcionamiento del mundo. Cuando la hegemonía del régimen de la visualidad de lo especial se impone como forma soberana de lo inclusivo, debilita cualquier intento por develar la autenticidad del campo de fenómenos, incluso afecta a las prácticas intersubjetivas y a las relaciones culturales. Otra singularidad de este enfoque consiste en la producción umbrales de conocimiento desconocidos que definen su funcionamiento en la 'exterioridad del trabajo teórico', es decir, aquello que habita por fuera y más allá de sus tradicionales campos y proyectos de adherencia y, especialmente, de los circuitos académicos. Tal como agrega, Chambers (2010), “aquí la pregunta de cómo, dónde, cuándo y por qué escribimos, enseñamos y pensamos, no es una nota a pie de página residual, sino que provoca una reconfiguración radical en el campo de estudios críticos" (p.254) que cuentan como parte del gran campo de significantes de lo inclusivo.

La inclusión instaura una nueva forma de materialismo encarnado, premisa que comparte con el feminismo que, es uno de los campos que participan en su gestación, instaurando una crítica significativa al humanismo sustancialista fuertemente imbricado en los planteamientos del régimen especial-céntrico cuya visión propugna un ser desviado de lo unitario, fijo y estático. En cierta medida, la recuperación que efectúa la visión de educación inclusiva que propongo del anti-humanismo, consiste en crear otras codificaciones para leer al sujeto educativo y social, por fuera y más allá de criterios universalistas de comprensión del ser, es un sistema de desvinculación del agente humano. El universalismo y la homogeneización que afectan a la trama de acontecimientos de la experiencia humana se fundan en una concepción liberalista-individualista clave en la matriz de regulación de lo especial. Siendo esta una de las principales objeciones del movimiento post-estructuralista.

La epistemología de la educación inclusiva consolida un marco de análisis para desafiar e interrumpir los modos canónicos de producción del conocimiento heredados por el logos, comparte con el feminismo la necesidad de crear conceptos que contribuyan a leer críticamente el presente, tarea que desde ninguna posición es ajena a lo político. Concebida así, "se convierte en el sitio insospechado de preguntas no autorizadas e invariablemente inoportunas" (CHAMBERS, 2010, p.255). Finalmente, la pregunta por el objeto teórico puede ser explicada a través de aquello qué es lo que piensa la educación inclusiva. Cuando la educación inclusiva 'piensa' nos referimos al objeto teórico, un dispositivo de pensamiento y de relación políticoheurístico. La construcción de su campo denota la presencia de un pensamiento colectivo. El poder transformador de lo inclusivo viene de su capacidad para pensar, el objeto teórico es aquello que fuerza el pensamiento, es lo producido por el investigador. En efecto, comenta Bal (2016) que,

[...] los objetos son participantes activos en el desarrollo del análisis en tanto que posibilitan la reflexión y la especulación y pueden resistirse a las proyecciones y las interpretaciones desquiciadas (si el analista se lo permite) y, así, constituir un objeto teórico de relevancia filosófica". (BAL, 2016, p.50).

Complementa la teórica cultural, agregando,

[...] un objeto teórico nos obliga a hacer teoría, pero también nos surte con los medios para hacerla. Por tanto, si estamos de acuerdo con aceptarlo desde el punto de vista teórico, produce efectos a su alrededor [...] [y] nos fuerza a preguntarnos qué es la teoría. Está planteado desde un punto de vista teórico; produce teoría, y necesita una reflexión sobre la teoría (Bois et ni. 1998:8). En la dinámica entre las obras en tanto que objetos, sus espectadores, y el momento: en el que estos se reúnen, acompañados por la agitación social a su alrededor, emerge un proceso de pensamiento colectivo con poder de convicción. La formulación de Damisch de su concepto de objeto teórico a veces parece sugerir que los objetos teóricos son objetos que 
las teorías han producido a nuestro alrededor. (BAL, 2016, p.122).

\section{La naturaleza epistemológica post-disciplinar de la educación inclusiva}

Si partimos de la afirmación que la educación inclusiva se resiste a la programaticidad teórica y metodológica, trabaja en la producción de dispositivos analíticos imaginativos y desafiantes, reconoce que sus formas de producción del conocimiento son el resultado de complejas operaciones políticas, culturales y heurísticas. El poder de la epistemología de la educación inclusiva no reside en la repetición del hecho heurístico de la forma edípica de lo especial, sino que, en la liberación de tal esencialismo heurístico. Cuando entendemos la educación inclusiva como educación especial la estamos condenando a repetir el mismo fallo, impulsando un monocéntrismo devenido en un singular esencialismo epistémico. La pregunta por las formas de construcción del conocimiento de la educación inclusiva explicita un enfoque distinto al de las disciplinas convencionales, aunque dialoga e interactúa con algunas de estas en algún momento determinando con sus diversas convergencias heurísticas. Este hecho exige la creación de otras formas metodológicas que brinden coherencia interna a la comprensión de su campo de fenómenos, se opone a la articulación de prácticas investigativas de carácter instrumental caracterizadas por capturar difícilmente la complejidad y profundidad de su heterotopicalidad de fenómenos. La educación inclusiva es un campo de complejas arenas movedizas analítico-metodológicas. La interrogante acerca de sí nos estamos enfrentando a una inter-disciplina, anti-disciplina, post-disciplina, trans-disciplina, etc., dependerá de cuál es su objeto.

La educación inclusiva al enunciar y escuchar su campo de fenómenos más allá de las disciplinas y en ocasiones en contra de estas, debido a la presencia de múltiples convergencias heurísticas, organiza su actividad en la exterioridad del trabajo teórico ${ }^{\mathrm{iii}}$-aquello que está más allá de su campo habitual de significantes, incluso fuera de lo especial y de lo educativo- inaugurando una singular modalidad constructiva de carácter postdisciplinar. La exterioridad del trabajo teórico permite enrutar la comprensión del conocimiento y los ensamblajes del campo a través de proyectos políticos y de conocimiento, metodologías y conceptos no autorizados con el objeto de desafiar las articulaciones en las que diversas unidades constructivas se convierten en parte de los objetos y propósitos específicos de la educación inclusiva. Cada una de sus contribuciones convergentes multiplican las perspectivas que trabajan a favor de la pseudo-cuadrícula de inteligibilidad legada por lo especial, la que, sin duda, produce un efecto de falsificación heurístico-metodológica y un sistema de errancias permanentes en torno a sus sistemas categoriales.

Las redefiniciones epistemológicas de la educación inclusiva asumen que sus impactos se encuentran lejos de lo estrictamente académico, son por esencia, transformaciones escalares que penetran en lo más profundo de los sistemas-mundo, afectando/ produciendo otros regímenes políticos, otras formas de vida, otros modos de relacionamientos y otras formas de subjetividad. Todo ello, asume problemas intelectuales, éticos, estéticos y paradigmáticos desconocidos. Las condiciones de audibilidad son claves para redescubrir el objeto auténtico del campo, este se escucha por fuera y más allá de las convencionales claves heurísticas y de campos académicos, políticos y culturales etc., lo que se traduce en cierta medida en la "donación, inteligibilidad y aceptabilidad a algunas disciplinas inmensamente significativas y aún polémicas innovaciones, asociadas al trabajo de los estudios culturales, el feminismo, el postestructuralismo y el poscolonialismo, en particular" (BOWMAN, 2010, p.246).

La dimensión 'post-disciplinar' ofrece múltiples desafíos a muchas posiciones establecidas en y alrededor del campo de significantes de lo inclusivo, explicitando una alta "sensibilidad a las complejidades de las problemáticas interrelacionadas de clase, feminismo, etnicidad, historia, traducción, trabajo comparado, teoría postestructuralista, cultura popular, literatura, cine y tecnología, en cualquier estudio cultural" (BOWMAN, 2010, p.231). En efecto, la construcción del conocimiento del campo da cuenta de la

[...] conciencia de las genealogías imbricadas y líneas de fuerza que han constituido y estructurado estos campos, y las presiones a menudo subterráneas y movimientos que 
condicionan y sobredeterminan tales campos académicos y otras distancias, relaciones, encuentros, hibridaciones, rupturas de los discursos culturales y consolidaciones (BOWMAN, 2010, p.231).

La práctica teórica de la educación inclusiva se elabora sobre un terreno de profundas y contingentes traducciones, rearticulaciones, giros y dislocaciones de lugares, geografías, conceptos, teorías, proyectos políticos, métodos, metodologías y objetos inconmensurables, evitando así, generalizar la función del campo tal como aparece en la intimidad del discurso mainstream. Este se caracteriza por generalizar la alteridad contribuyendo a difundir una visión opresiva y negativa de la diferencia una alteridad generalizada-. La inclusión que más conocemos y de la que más hablamos denota una crisis en la comprensión de su objeto teórico, empírico y analítico, así como, en su praxis, en su dimensión performativa y en el cuerpo de significantes que definen la fuerza del argumento en términos contra-hegemónicos. La educación inclusiva mainstream se caracteriza por un mensaje de propaganda, un argumento directo y una afirmación difícil de penetrar en la profundidad de los engranajes del sistema educativo. La epistemología de la educación inclusiva promueve una nueva configuración crítica ofreciendo posiciones a través de lecturas muy cercanas pero amplias de todo tipo de objetos, interpelando un corpus de "restricciones por demarcaciones disciplinarias contingentes" (BOWMAN, 2010, p.234).

En la construcción del conocimiento de la educación inclusiva, la unión, el encuentro, la relación, el movimiento, la examinación topológica, la rearticulación y el giro revelan complejas, desconocidas y profundas relaciones heurísticas, metodológicas y discursivas que albergan múltiples problemas y campos documentando "interconexiones implícitas y explícitas entre, así como brechas, hiatos, aporías y barreras a través de supuestamente "reinos" separados" (BOWMAN, 2010, p.235); confirmando “explícitamente una línea de razonamiento que ha Stuart Hall ha expresado la necesidad de decir "sí" y "no" a la necesidad de teorización y análisis académico riguroso y a las urgencias y exigencias de cuestiones éticas y políticas" (BOWMAN, 2010, p.235). El permanente choqué y la transgresión de los límites de diversas geografías intelectuales dispersas exigen una analítica que actué en proximidad con la metáfora propuesta de 'interacciones agonísticas productivas' y por los itinerarios de destino de la información que informa su razón teórica.

¿Qué es lo que cubre el sintagma educación inclusiva? Si partimos de la afirmación que la educación inclusiva no refiere necesariamente a cualquier cosa en particular, sino que posee una doble especificidad contextual. En su intimidad muchas "cosas difusas también parecen inevitable e ineludiblemente interconectadas, interimplicadas e interrelacionadas. Porque a pesar de ser tan divergentes y dislocados, estos fenómenos heterogéneos a menudo parecen converger" (BOWMAN, 2010, p.239). La complejidad de los territorios heurísticos de lo inclusivo queda determinada por campos de relaciones, conexiones, separaciones, traducciones y giros inesperados, lo que insta a recuperar la pregunta acerca de "qué sucede cuando un campo, que he estado tratando de describir direcciones en constante cambio, y que se define como un proyecto político, trata de desarrollarse como una especie de intervención teórica coherente" (BOWMAN, 2010, p.240).

La educación inclusiva puede ser definida como un proyecto académico de naturaleza post-disciplinar, un objeto excéntrico, mutativo, polifacético, polimórfico y ambivalente, un espacio diaspórico de naturaleza multiposicional, multilocalizada, abierto, cargado de sistemas de redoblamientos, mecanismos heterogenésicos, etc., dando cuenta de una singular estructura de heterogeneidad radical. El espacio heurístico de la educación inclusiva queda atravesado por recursos constructivos extremadamente diferenciados que colaboran produciendo un nuevo ensamblaje. La educación inclusiva epistemológicamente puede ser definida como un dispositivo macro-educativo, es decir, un aparato de recognición de las formas teóricas y metodológicas del conocimiento educativo, un espacio para el estudio de las formas imaginativas y de los futuros de la educación, la subjetividad y la producción de otros mundos. Como campo de investigación opera en un singular doble vínculo: es capaz de convertirse en un dispositivo de meta-receptividad heurística aglutinando por rearticulación una infinidad de campos (post-)críticos y proyectos de conocimiento en resistencia. Mientras que, por otro, circunscribe a una amplia variedad de problemas que escapan a 
preocupaciones eminentemente educativas, es decir, abarca una totalidad de prácticas que ensamblan otro mundo y reglas de funcionamiento estructurales y microprácticas, incluso de los marcos disciplinares que se encargan de su estudio definiendo muy claramente sus capacidades morfo-genéticas propias generando mecanismos heurísticos desconocidos e independientes.

La educación inclusiva a diferencia de otros campos de investigación no puede definirse como un espacio de recepción inerte de formas exteriores. Sin duda, este punto es uno de los más sustantivos en la construcción del conocimiento auténtico de la educación inclusiva, el que actúa “alterando y transformando formaciones de pensamiento, discurso y acción" (FARÍAS, 2008, p.77).

\section{El prejuicio "especial” de la educación inclusiva y su esencialismo epistémico}

Si partimos del reconocimiento que cualquier forma de esencialismo contribuye a la reproducción de la violencia, o bien, las ayuda a persistir en formas que violenta a la raza, la diferencia, etc. En superación de esta articulación de carácter humanista clásico es necesario "averiguar cómo garantizar que el potencial de los antagonismos violentos los que siempre amenazan con surgir en las fronteras de las culturas y transformando el uso del vocabulario" (BOWMAN, 2010, p.241). Documenta, además, cómo el sentido de lo especial se convierte en la voz depositaria única del significado de lo inclusivo. Esta es la tónica habitual en las estructuras académicas, en los programas de investigación, en los estudios de pre- y post-graduación y en las políticas públicas a nivel mundial. Cada uno de ellos, a su forma, síntomas de un proyecto neocolonizador en la que su acción se afirma mediante la mirada potente, la fuente de significado y la acción. El prejuicio de lo especial no es otra cosa que "una pretendida pureza de representación del pensamiento o de la estructura de la realidad" (DERRIDA, [s.a], p.34).

El prejuicio de lo especial puede ser leído en términos de una auto-justificación ideológica propiedad de un proyecto esencializador, una zona de tensionalidad crítica entre las formas adjetivales de lo 'especial' y lo 'inclusivo', una espacialidad multiposicional en la que se irritan y tensan permanentemente ambas fronteras heurísticas las que, si bien, demuestran un estatus parasinónimos; su capacidad analítica y metodológica actúa en términos diferentes. Si este problema de relación ha persistido se debe en cierta medida a una debilidad de autocomprensión acerca de la consciencia de lo inclusivo, fundamentada en una singular trama de edipización epistemológica, que documenta cómo su trabajo intelectual revela una posicionalidad que obstaculiza la comprensión de la naturaleza epistémica del campo, al tiempo que desafía la posicionalidad soberana que da legibilidad a un pseudo-efecto de producción teórica de lo inclusivo alojado en cegueras y vanidades epistemológicas sin fundamento alguno. Considero oportuno desplegar otra acción: desprovincializar lo inclusivo de lo especial o también denominado el escándalo epistémico persistente, el que trabaja sobre signos de ignorancia morfo-analíticos, en superación de ello propongo desplegar múltiples caminos que conduzcan a una serie de enfrentamientos disruptivos abriéndose a la posibilidad teórica de la desterritorialización precedida por la multiplicación de perspectivas lo que desestabiliza a lo especial como grilla de inteligibilidad.

El prejuicio de lo especial se convierte en un argumento primitivo y marginador de otras identidades complejas y posibilidades de aproximación al mundo conocido. Construye, además, un significante cuya fuerza analítica y visual logra eclipsar el verdadero índice de singularidad de los territorios de lo inclusivo sometiéndolo a un argumento fácil de difundir que no establece ningún punto de relación con la verdadera función del campo. Deviene en un reemplazo de significantes arbitrarios traducidos como un sistema de alucinación que débilmente se inquieta por la pregunta acerca de la voz y rostricidad de lo inclusivo, consolidando un estatus de inferioridad propiedad del régimen especial-céntrico. Epistemológicamente, la educación inclusiva desestabiliza el logos. Sin duda, esta es una de sus principales tareas críticas. Si el prejuicio de lo especial se convierte en la forma soberana de significar las luchas del campo, entonces, será necesario consolidar el estatus heurístico y el índice de singularidad de lo inclusivo para evitar la cooptación de su campo de actividad y significantes en una rostricidad que no le pertenece. Observo también necesario destrabar la relación de complicidad ente ambas formas adjetivales, rompiendo de esta manera con el "deseo de conservar algo que es, paradójicamente, a la vez inefable y no trascendental" (SPIVAK, 1998, p.337). Esto nos obliga a desplegar un itinerario acerca del discurso de la presencia 
genealógica de lo especial en la constitución de lo inclusivo enmarcado en un problema heurístico específico para producir la liberación a nivel intracientífica y epistemológica análoga en la que operan y acontecen ambos términos. ¿Cuál es la que ley rige semejante contradicción?

Parte del prejuicio especial puede explicarse a través de la afirmación que Chow (2010), efectúa en torno la noción de verdad esencial que delimita las posibilidades de legibilidad de cada ser. Es esto, lo que funda parte del régimen especialcéntrico sobre el que hoy se erige buena parte de la argumentación de la educación inclusiva. Para ello, es necesario mover la frontera de sus significantes institucionalizados para proceder a desfamiliarizar lo familiar que participa de la argumentación equívoca del término sancionado por diversos circuitos académicos. Continuamente ofrezco un sí a favor de la continuidad de la educación especial como territorio independiente que debe ser reformulado a la luz del cuerpo categorial, metodológico y heurístico de lo inclusivo, al tiempo que ofrezco un 'no' a sus propios prejuicios y contingencias, traducidas como múltiples errores de relación entre ambos términos. Muchos de sus puntos ciegos inaugurales habitan un complejo espacio de opacidad en el que

[...] las exigencias políticas tensas, sentidas, vividas y muy reales $y$ urgencias que se congregan, condensan y brotan en torno a aspectos y cuestiones de raza, etnia e identidad cultural. Pero este sí va acompañado de un claro no a cualquier pensamiento esencialista, o pensamiento que ayude a las nociones de raza, etnia y nacionalismo para persistir en formas que son violentas ya sea física, institucional, legislativa o intelectualmente frente a otras etnias, pueblos, identidades $\mathrm{u}$ otros pensamientos sobre uno mismo y los demás (BOWMAN, 2010, p.241).

En cierta medida, el 'prejuicio de lo especial' es cómplice con múltiples sistemas de indiferencia sobre identidades y mecanismos de producción cultural que van más allá del sujeto soberano de lo especial: la discapacidad. El nuevo contextualismo epistemológico de la educación inclusiva informa que, el mainstream discursivo se funda en una coalescencia cómplice con el humanismo clásico devenida en la matriz de esencialismo-individualismos en la que se adoptan como únicas formas ontológicas y tramas de visualidad legitimadas de diferencias universales, omitiendo la pregunta por las formas de devenires encarnados y el materialismo subjetivo que cruza nuestra relación con los criterios de redefinición y legibilidad permanente del ser. Se observa un acento óntico indiferente con la multiplicidad de expresiones del ser, documentando una ignorancia sancionada por diversos circuitos académicos a nivel mundial. Considero oportuno plantearme la interrogante acerca de las posibilidades de descolonización ontológicas de la educación inclusiva y su impacto en la estructura de provisión educativa interrumpiendo en las lógicas de producción del conocimiento. El prejuicio especial es, en cierta medida, una consecuencia directa del canibalismo metafísico referido a la comprensión del ser, produciendo de esta forma, otro que nunca se estudia o deconstruye seriamente en la intimidad de los debates académicos del campo, convirtiéndose en algo incómodo e irritante que no insiste en un cierre teórico final. Todo ello, es el resultado de desiguales líneas de fuerza en la comprensión ontológica de lo inclusivo.

Finalmente, sostendré que, epistemológicamente, la educación inclusiva busca poner fin a los prejuicios analíticos tradicionales que configuran su grilla de inteligibilidad, entre los que destacan: a) la educación inclusiva no es más que una mutación avanzada de lo especial, construyendo un nuevo rostro sobre lo inclusivo que jamás alcanza a develar la autenticidad de esta y b) la continuidad de la trampa edipizadora de lo especial y su legado regenerativo a través de la matriz de esencialismos-individualismos. Al concebir la educación inclusiva a través de la montura epistémico-didáctica de lo especial, se abre a un interrogatorio complejo y abierto que difunde una interrupción en los discursos legitimados a través de los cuales se busca definir, explicar y, en última instancia, controlar su trama heurística, metodológica y pedagógica. En efecto, el objeto de la educación inclusiva "se niega a permanecer impotente. Insiste y resiste a la categorización y detención conceptual" (CHAMBERS, 2010, p.257) efectuado por el idioma de lo especial y sus múltiples correlatos para vida pedagógica, desestabilizando el edificio epistémico del conocimiento de lo especial y lo neo-especial potencias colonizadoras-, el que históricamente se ha negado a reflexionar en torno a las preocupaciones 
de lo inclusivo. Uno de los propósitos heurísticos de la educación inclusiva consiste en reelaborar tal red de producción del saber y, con ello, transformar su rostricidad hacia una comprensión intelectual y política alterativa. Esta necesita volverse consciente de sí misma, es decir, inquieto e incómodo, en su propio entorno y naturaleza.

\section{Una zona de tensionalidad crítica: la extraña imposición del rostro de lo especial para fundamentar la tarea de lo inclusivo}

La noción de zona de tensionalidad crítica que empleo en esta ocasión, ha sido introducida por la teórica cultural Nelly Richard, para explicar cómo los límites de dos o más campos del conocimiento se irritan, tesan y chocan en su interacción. Con motivo de este trabajo emplearé esta noción para documentar cómo la supuesta interacción analíticometodológica establecida entre lo especial y lo inclusivo suscita más contradicciones, tensiones y discontinuidades que certezas y sistemas de estabilización que proporcionen formas condiciones y lexicales para explicar la función de cada adjetivo con claridad. Lo cierto, es que la adjetivación 'inclusiva' no es el resultado de mutaciones más avanzadas de la educación especial, cuando el argumento se posiciona en esta dirección, emerge una peculiar forma de edipización heurística suscitando nuevas formas de malestar contextual entre ambos adjetivos. La edipización es siempre una forma de castración, de restricción o de control de algo, es, también, un sentimiento de inadecuación, de sentirse incomprendido, o bien, la posesión de una imagen desajustada, negativa o contradictoria.

La noción de edipización heurística de la educación inclusiva es introducida por Ocampo (2020), caracterizada por asignar un sentimiento de castración, extrañamiento y resentimiento, su trama argumental es débil en cuanto a establecer aquello que le falta. Lo que hoy tenemos es que la inclusión completa a la educación especial -visión neo-especial-, imponiendo parte del deseo de esta, respondiendo a una rostricidad que no le pertenece, generando una imagen desajustada y paradojal. Aquí el problema es hacerse deseo de deseo, ¿qué quiere lo especial de lo inclusivo?, ¿se encuentra sometido a una ley arbitraria de regulación heurística? Ciertamente los territorios de lo inclusivo se encuentran regulados y sometidos a los significados proporcionados por lo especial -fuerza de travestización y pseudocompletud-. Nos enfrentamos a un capricho epistémico devenido en un escándalo persistente en sus agendas de investigación. Es necesario transitar hacia la sustitución de un significante por otro significante; necesita aceptar que el objeto de lo inclusivo no es lo especial, y con ello, subvertir la figuración imaginaria que esta traza.

Las formas de edipización de lo inclusivo con lo especial describen formas de relacionamiento y cadenas de herencias heurísticas cuyo resultado deviene en un halo ambivalente de deseos amorosos y hostiles sobre la función de lo especial. Nos enfrentamos a una relación edípica, suscitando formas de rechazo y rivalidad desprendidas de esta extraña e injustificada relación. Esta forma de edipización posee la capacidad de estructurar nuestro sistema imaginario, material y pedagógicocultural, incluso, presenta repercusiones a nivel de su gramática y lenguaje devenida en un sentimiento persistente de inadecuación sobre su alcance y función en el mundo actual; refiero a un corpus de posiciones potencialmente contradictorias en torno a la fuerza teórica de la educación inclusiva. Para explorar tal constelación será necesario atender a las formas de regreso e imposición a patrones imitativos de la figuración de lo especial como parte de lo inclusivo que son impuestos por un régimen especialcéntrico, mecanismo que denomino: proceso de edipización de lo inclusivo.

Las nociones de 'zona de tensionalidad crítica' y 'edipización de lo inclusivo' comparten el sentido de enemistad, incomodidad y tirantez que se suscita de la interacción de la interacción y diálogo entre las formas adjetivales 'especial' e 'inclusivo'. La tensionalidad que observo a partir de los relacionamientos heurísticos entre ambas nociones explicita un sistema de resistencia entre sus significantes analíticos, bordes metodológicos, categorías y perspectivas de tratamiento las que a nivel epistemológico se irritan y molestan continuamente, incluso, son el resultado de profundas incomprensiones y devaluaciones entre ellas. Ejemplo de ello, es el argumento que sitúa desde el lente de lo inclusivo a la satanización de lo especial, trazado un itinerario radical de destrucción que, en cierta medida, se convierte en un argumento vacío y nefasto. Muchos de sus conflictos pueden situarse en relación a falacias que legitiman un sistema de autoridad que no es tal, además, de conflictos de 
lenguaje y posición entre ambas. Estos argumentos pueden ser reducidos a una obstrucción en los coeficientes de poder que habitan en la interioridad de cada una de las formas adjetivales. Lo cierto es que el significante mainstream de lo inclusivo goza de mayor reconocimiento en las estructuras académicas y prácticas investigativas, pero, su relleno heurístico y ejes de tematización provienen de aquello que su significante sataniza y desprecia arbitrariamente: lo especial. En esta contradicción de significante hay algo llamativo, son los sentidos procedentes de lo especial los que gozan de mayor reconocimiento social a la hora de fundamentar la tarea de lo inclusivo, producto que esta última, carece de bloques de reflexividad que describen su índice de singularidad convirtiéndose de esta manera en un discurso bastante trivial. La génesis de este conflicto es producto de los problemas visuales del campo. Lo inclusivo debe ser considerado en relación con lo no-especial,

[...] es plural ya que reconoce diferentes modalidades de producción de conocimiento. Cuestiona la idea que los únicos conocimientos relevantes son aquellos producidos dentro de las modalidades y etiquetas derivadas del mundo académico. No sigue el supuesto de una jerarquización que privilegia epistémicamente el conocimiento de los expertos y las disciplinas académicas sobre otras modalidades de conocimiento (RESTREPO, 2016, p.69).

\section{Conclusiones - Una tarea crítica: desprovincializar lo inclusivo de lo especial}

A lo largo del trabajo he documentado que una de las principales obstrucciones en la comprensión de la educación inclusiva reside en la ausencia de bloques de reflexividad que permitan discutir en términos más transgresores acerca de su capacidad y singularidad teórica. Sumado a ello, el problema ligado a los mecanismos de edipización de lo especial y la proliferación de sus múltiples prejuicios que actúan en términos de presiones onto-políticas y desviaciones analítico-metodológicas agudizando prácticas de ininteligibilidad sobre su posible naturaleza y red objetual.
La tarea crítica que tenemos ante nosotros es compleja bajo todo punto de vista. En cierta medida, retoma uno de los propósitos heurísticos de mayor alcance de la educación inclusiva como es el relativo a la desestabilización del logos, las concepciones de conocimiento universalistas y a la red de conceptos que son empleados para fundamentar su tarea. 'Desprovincializar' es una metáfora que posibilita comprender los movimientos, giros, desplazamientos y descentramientos que emergen al preguntarnos por la singularidad de los bloques de reflexividad de la educación inclusiva, produciendo un desplazamiento y descentramiento epistémico-metodológico, incluso político, sobre una fuerza hiperrealista de lo que cuenta como inclusión travestida con la fuerza de lo especial. Esta relación edípica es restrictiva a la hora de navegar en la inmensidad intelectual que designa lo inclusivo. La potencia analítica que reside en la 'desprovincialización' supera las formas de fetichismo y desprovincialización proporcionadas por el atrapamiento edípico y la fuerza mimética que suscita la articulación neoespecial, sino que, trabaja para encontrar su pensamiento propio. Otra tarea consiste en documentar cómo la forma como usualmente se ha pensado la producción, circulación y apropiación del conocimiento, está marcada por una epistemología cómplice con formas de concientización y disfraces ontológicos de la matriz de esencialismos-individualismos. Sumado a ello, la asepsia cientificista y normativa que le atribuye indebidamente a lo especial un estatus de condición soberana, generando una diversidad de prejuicios en la producción de su saber. La educación inclusiva desafía el argumento que imputa una concepción ético-moral de los individuos y las sociedades.

Una de las tensionalidades críticas más persistentes de la educación inclusiva refiere a las complejas condiciones que definen la situacionalidad de su campo de conocimiento -de carácter aléctico-. Esta premisa involucra un cuestionamiento acerca de las coordenadas sociopolíticas ligadas a la producción del conocimiento, discutiendo acerca de quien lo produce, en qué contexto y para quién - esta premisa es la que define que gran parte de su campo de fenómenos reside en la subjetivación del ser-. Tales dimensiones serán cruciales al momento de discutir acerca de los dispositivos visuales de la educación inclusiva y del tipo de imágenes que de ella se desprenden. El conocimiento de la educación inclusiva es algo que se marca profundamente desde una multiposicionalidad de los sujetos que 
lo producen, es una praxis cognitiva subjetivada y corporalizada que necesita encontrar sus códigos semiológicos concebidos como fórmulas de reinvención de lo ontológico y de sus criterios de legibilidad. Empresa que es informada por singulares dispositivos de visibilidad y visualidad. El conocimiento de la educación inclusiva está situado de múltiples maneras, trazando una distinción fundamental a nivel ontológico.

Regresemos a la premisa fundacional de este apartado. Los términos 'provincializar' y 'desprovincializar' no deben ser concebidos en términos opositivos y dicotómicos, sino que se convierten en una estrategia analítica de carácter multiposicional para indagar en una multiplicidad de argumentos que permitan pensar la naturaleza de los territorios de lo inclusivo más allá del atrapamiento edípico que efectúa lo especial y, con ello, desnaturalizar las narrativas epistemológicas que montan mediante un efecto de double exposures ambas rostricidades, contribuyendo a crear nuevas formas de ininteligibilidad sobre su relación. Contribuye a interrogar las parroquialidades analíticas que dicha montura y relación instituye, produciendo un relativismo heurístico sin precedentes.

Bajo ningún término, la tarea desprovincializadora promueve el rechazo de la educación especial y su razón teórica que es analítica e intrínsecamente reproductor del régimen normo-céntrico. Desprovincializar entraña la tarea de desplazar lo 'especial' del centro de regulación teórica, metodológica, categorial, ética y pedagógica. Cuando confundimos lo especial con lo inclusivo, articulamos una visión hiperrealista materializada en una ficción de aproximación a un gran campo de objetos, no solo aquello que cuenta como parte de las geografías, lugares y comunidades que forman parte de lo normo-céntrico y de la matriz de esencialismosindividualismos. Tal desplazamiento implica un redibujamiento de sus genealogías que constituyen el nido de sus múltiples sistemas de binarización en la comprensión de los problemas educativos.

La visión neoespecial es la más difundida a nivel global suscitando una serie de contradicciones producidas por un argumento que niega la inconmensurabilidad cómo principal sistema de producción de lo inclusivo. Al mismo tiempo reconoce que, es el resultado de una elaboración colonial. Son estas las que han hecho posible la vigencia e impronta del régimen normo-céntrico en todo su esplendor.
La educación especial no es la entidad preexistente ni autoconsciente de la educación inclusiva que existe a partir de una exterioridad ontológicamente desconocida; un singular efecto de borramiento de relaciones que son subsumidas en su comprensión heurística. Hasta las categorías de pensamiento empleadas para comprender la educación inclusiva resultan insuficientes.

La noción de pensamiento propio es crucial para superar cualquier forma de caricaturización referida al ámbito de formalización del pensamiento académico de la educación inclusiva. Tal como he enunciado en diversos trabajos no es posible hablar de un pensamiento propio en lo específico de la educación inclusiva debido a la ausencia de bloques de reflexividad acordes con su singularidad heurística. Este hecho ha documentado que, en gran medida, el campo de significantes acerca de lo que cuenta y puede ser enunciado como parte de lo inclusivo ha sido estipulado en relación en el pensamiento de lo especial, una empresa de control esencialista-individualista que consagra un corpus de configuraciones de carácter normo-céntricos, estableciendo una pertenencia a sectores concretos atravesados por la imagen de pensamiento de lo vulnerable y de las alteridades abyectas, descuidando así, una comprensión pormenorizada acerca de las condiciones de variación, disrupción y alteratividad del ser fundado en el esquema onto-semiológico y político de carácter procesal denominado: 'singularidades múltiples'.

El pensamiento de la educación inclusiva a diferencia del proporcionado por la educación especial devela un marcado carácter relacional, no es esencialista, es posicional, heterogéneo, contingente y contradictorio. Cada una de estas características informan que la naturaleza de su pensamiento se define por momentos de singulares disputas que saltan y se movilizan hacia rumbos desconocidos, denotando una posición móvil e itinerante de frontería. El pensamiento propio de la educación inclusiva es un cómo orientado por un para qué, antes de un contenido o eje de tematización previamente definido, donde el contenido o lo previamente delimitado constituye parte de la ficción teórica desprendida de la provincialización de su red objetual en lo especial. A estas alturas, este argumento parece de Perogrullo. Es importante reconocer el campo de obstrucciones que dicha interacción suscita -el relativismo epistémico-. 
El mainstream teórico de lo inclusivo que no es otra cosa que un conjunto de argumentos de sentido común, inaugura un nuevo relativismo epistémico caracterizado por celebrar cualquier cosa como parte de su campo de fenómenos, en una suerte de éxtasis teórico. El pensamiento propio de la educación inclusiva no puede obviar que hoy no disfruta de condiciones adecuadas para su consolidación acorde a sus demandas de autenticidad epistemológica y metodológica. En cuanto dispositivo heurístico y político articula un diagrama de continuidad de varias tradiciones de pensamiento, interpretando crítica y contextualmente esos legados.

La inclusión y la educación inclusiva son fenómenos cambiantes y dinámicos, ambos constituyen parte sustantiva de su esencia heurística. Si bien, son términos cambiantes y dinámicos que demuestran en la interioridad del campo, usos y efectos diferentes, analíticamente, dan cuenta del movimiento incesante sobre la cual se construye su conocimiento, forjando una imagen de pensamiento inacabado, imprevisible e inquieto. Por otra parte, uno de los rasgos distintivos del pensamiento inclusivo otorga un lugar destacado al cambio y a la transformación, propiedades claves para que este actúe materialmente como un proyecto de justicia educativa y social.

Sin pretender actuar como un sistema de clausura, quisiera sostener como último tópico de trabajo que la educación inclusiva plantea un conjunto de imágenes, signos y dispositivos onto-semiológicos contradictorios. Tal contradicción emerge cuando nos preguntamos acerca de su grilla de inteligibilidad epistémica cuyos impactos afectan a lo ontológico y las condiciones de visualidad que definen sus imágenes. Estas son formas de producción del conocimiento lo que permite sostener que la construcción visual disponibilizada sobre educación inclusiva es equívoca y contradictoria trivializando sus preocupaciones. Aunque la visualidad está en el corazón de la educación inclusiva, se convierte en aquello que lo otorga sentido a sus unidades de significación y legibilidad de sus objetos, exige de la configuración de una metodología para hacer frente a tal tarea. La inclusión debe avanzar hacia la elaboración de una estrategia que nos permita articular una comprensión global de sus modos de producción de la subjetividad. En otras palabras, profundizar en las dinámicas de configuración y procesos de singularización del ser, siendo justamente esto último, lo que la educación inclusiva es incapaz de comprender a través de sus modos e itinerarios de definición del ser regulado por un sistema de equivalencias categoriales.

\section{Referencias}

BAL, M. El esencialismo visual y el objeto de los estudios visuales, 2003. Disponível em: <https:// comunicacionymedios.uchile.cl/index.php/RCM/ article/view/11547/32136>

BAL, M. Conceptos viajeros en las humanidades: Una guía de viaje. Murcia: Cendeac, 2009.

BAL, M. Tiempos trastornados: Análisis, historias y políticas de la mirada. Madrid: Akal, 2016.

BAL, M. Y-cidad: los múltiples sentidos de «y». Versants - Revista Suiza De Literaturas românicas, v. 65, n. 3, p. 187-207, 2018.

BAL, M. Lexicón para el análisis cultural. Madrid: Akal, 2021.

BOWMAN, P. Reading Rey Chow. Postcolonial Studies, v. 13, n. 3, p. 239-253, 2010.

CHAMBERS, I. Theory, thresholds and beyond. Postcolonial Studies, v. 13, n. 3, p. 254-264, 2010.

CHOW, Rey. Reading Rey Chow: Visuality, postcoloniality, ethnicity, sexuality. New York: Peter Lang, 2010.

DERRIDA, J. La Violencia Del Discurso Metafísico. [s.a]. Disponível em: <https://redaprenderycambiar. com.ar/derrida/comentarios/peretti.htm>

FARÍAS, I. Hacia una nueva ontología de lo social Manuel De Landa entrevista. Persona y Sociedad, v. XXII, n. 1, p. 75-85, 2008.

FELMAN, S. «To Open the Question». Yale French Studies: Literature and Psychoanalysis. The Question of Reading: Otherwise, n. 55/56, p. 5-10, 1977.

HERNÁNDEZ, M. Á. Introducción. Mover la frontera: actuar aquí y ahora. In: BAL, M. Tiempos trastornados. Madrid: Akal, 2016. p. 5-13.

MENGUE, P. Deleuze o el Sistema de lo múltiple. Buenos Aires: los cuarenta libros, 2008.

OCAMPO, A. En torno al verbo incluir: performatividades heurísticas de la educación inclusiva. Quaest. disput, v. 13, n. 27, p. 18-54, 2020.

ORLANDI, E. Análisis del discurso: Principios y procedimientos. Santiago: LOM/UMCE, 2021. 
PANAYOTOV, S. Diagram. New Materialism. How matter comes to matter. 2016. Disponível em: $<$ https://newmaterialism.eu/almanac/d/diagram. html>

RAJCHMAN, J. Constructions. Cambridge, MA, MIT Press, 2004.

RESTREPO, E. Descentrando a Europa: aportes de la teoría postcolonial y el giro decolonial al conocimiento situado. Revista Latina de Sociología (RELASO), v. 6, n.1 p. 60-71, 2016.

RICHARD, N. El conflicto entre las disciplinas. Revista Iberoamericana, v. LXIX, n. 203, p. 441447, 2003.

\footnotetext{
i Primer centro de investigación creado en Chile y en América Latina y el Caribe (ALAC), dedicado al estudio teórico y metodológico de la educación inclusiva, articula su trabajo desde una perspectiva inter-, post- y para-disciplinar. Institución internacional reconocida y con estatus afiliativo por el Consejo Latinoamericano de Ciencias Sociales (CLACSO) y por el International Consortium of Critical Theory Programs (ICCTP), EE.UU.
}

SPIVAK, Gayatri. ¿Puede hablar el subalterno? Revista Colombiana de Antropología, v. 39, p. 297 364, 2003.

TUCK, E.; YANG, W. Decolonization is not a metaphor. Decolonization: Indigeneity, Education \& Society, v. 1, n. 1, p. 1-40, 2012.

WILLIAM, T. Literature and Psychoanalysis: Open Questions. 2017. Disponível em: <https:// euppublishingblog.com/2017/11/07/literaturepsychoanalysis/>

ZEMELMAN, H. Los horizontes de la razón. I. Dialéctica y apropiación del presente. México: Antrophos, 1992.

ii Idea que extraigo Braidotti.

iii Noción que tomo prestada de Iain Chambers (2010). 